\title{
Title: Comparative study of fatty acid composition, total phenolics and antioxidant capacity in rapeseed mutant lines
}

\section{Running title: Biochemical properties of rapeseed mutants}

\author{
Souhail Channaoui ${ }^{1,2}$, Lahcen Hssaini ${ }^{1}$, Leonardo Velasco ${ }^{3}$, Hamid Mazouz ${ }^{2}$, Mohamed El \\ Fechtali $^{1}$ and Abdelghani Nabloussi ${ }^{1 *}$ \\ ${ }^{1}$ Research Unit of Plant Breeding and Plant Genetic Resources Conservation, National Institute of Agricultural \\ Research, Regional Agricultural Research Center of Meknes, Meknes, Morocco \\ ${ }^{2}$ Laboratory of Plant Biotechnology and Molecular Biology, Department of Biology, Faculty of Science, \\ University Moulay Ismail, Meknes, Morocco \\ ${ }^{3}$ Instituto de Agricultura Sostenible, Consejo Superior de Investigaciones Científicas (CSIC), Córdoba, Spain \\ *Correspondence: abdelghani.nabloussi@gmail.com
}

\begin{abstract}
There is limited variability within rapeseed germplasm in Morocco. Induced mutation was recently used to generate novel genetic variability and develop mutant lines combining desirable traits. In this context, nine rapeseed promising advanced $\mathrm{M}_{2}$ mutants lines and the wild-type variety 'INRA-CZH2' were evaluated for their seed oil content, fatty acid composition, total phenolics content (TPC), and free radical scavenging activity (FRSA) determined by 2,2-diphenyl-1picrylhydrazyl (DPPH) and 3-ethylbenzothiazoline-6-sulfonic acid (ABTS) methods. The results showed significant variability, among all mutants, in seed oil content (from 38.14 to $42.04 \%$ ) and in fatty acids (SAFA $=5.49-10.99 \%$, MUFA $=50.33 \%$ - 71.62\%, PUFA $=22.89 \%$ - 38.68\%). The mutant H2M-5 exhibited the highest fraction of MUFA and lowest proportion of SAFA and PUFA, while the mutant H2M-4 showed the highest SAFA and PUFA amounts and lowest MUFA level. TPC varied from 2.16 to $4.35 \mathrm{mg}$ GAE/100 g. The highest amount was found in the mutant $\mathrm{H} 2 \mathrm{M}-1$, which is about twice, compared to all other mutants and the wild-type variety. Free radical scavenging activity (FRSA) differed significantly among samples and the variations observed for DPPH and ABTS methods were 40.5-59.28\% and 40.31-59.86\%, respectively. FRSA was positively correlated to TPC in sampled oils $(\mathrm{r}=0.801$ and $0.802, \mathrm{p}<0.01)$. This is the first report emphasizing biochemical potentialities of rapeseed varieties and novel mutants in Morocco. H2M-1, H2M-4 and H2M-5 were proposed for rapeseed national breeding program as they showed higher levels in some biochemical traits of interest.
\end{abstract}

Keywords Rapeseed, Mutant lines, Fatty acids, Polyphenols, Antioxidant capacity 


\section{Introduction}

Rapeseed (Brassica napus L.) has become one of the most important sources of vegetable oil worldwide, with a substantially increased production over the last 39 years, which currently reached six times the production recorded in 1980 (Wanasundara et al., 2016). Due to the extensive breeding and cultivation programs, the worldwide rapeseed production was around 69 million tons (FAOSTAT, 2018). In Morocco, it was introduced as a promising oilseed crop that showed a good adaptation and a great potential allowing it to contribute significantly to the improvement of vegetable oils production. This strategy intended to reduce the gap between local production and the consumption of edible oil.

Rapeseed is a good source of edible vegetable oil, for human consumption, and of proteins, for feed industry. Besides, it has recently become an interesting source of biodiesel (Huang et al., 2016). The edible and processing quality of rapeseed oil is mainly related to the fatty acids composition of triacylglycerol lipids (Lee et al., 2018). Like as other oilseeds, the development of rapeseed with altered lipid composition has been the subject of intensive research in the last three decades due to its high industrial and nutritional importance (Liu et al., 2001; Nesi et al., 2008). Many authors stressed that the fatty acids composition varied among cultivars and changed according to environmental conditions (Zanetti et al., 2009). In general, oil from 00quality oilseed rape contains low levels of saturated fatty acids (SAFA= 5-10\%) and high amounts of monounsaturated fatty acids (MUFA $=44-75 \%)$ with a significant fraction of oleic acid $(18: 1=43-74 \%)$. It also contains a moderate amount of polyunsaturated fatty acids (PUFA $=22-35 \%)$, with a significant fraction of linolenic acid (18:3 = 9-13\%) (Deng and Scarth, 1998; Zanetti et al., 2009; Wittkop et al., 2009; Lee et al., 2018). The major unsaturated fatty acids in seeds are of great importance for nutritional and industrial applications. Whereas breeding programs have mainly focused on new varieties with high oleic acid content, the high erucic acid content has traditionally been required for industrial applications (Röbbelen and Kräling, 1993). However, the harmful effect of erucic acid and the beneficial effect of oleic acid, from a nutritional point of view, have incited researchers to develop new varieties with very low level of erucic acid and high oleic acid content. Indeed, the high oleic acid content of rapeseed oils render them highly stable against oxidation, and make them favorable for frying food at high temperatures and for producing biodiesel (Warner and Knowlton 1997; Graef et al., 2009). This feature is of great use for the cosmetic and pharmaceutical industries (Röbbelen and Kräling, 1993). Furthermore, high oleic acid rate combined to low amounts of linolenic acid are together highly desirable for biodiesel production, since a good low-temperature fluidity can be obtained 
(Jang et al., 2010; Lee et al., 2010). Therefore, the modification of oleic acid (18:1) and linolenic acids (18:3) levels in seeds is one of the major breeding goals to increase the quality of rapeseed (Yang et al., 2012).

Phenolic compounds, which are considered as major plant secondary metabolites, play an important role as defense constituents. Rapeseed contains more phenolic compounds than the other oilseeds (Yang et al., 2014). Sinapic acid and its derivatives, mainly sinapine, are the major polyphenols compounds (Chen et al., 2014; Yang et al., 2014). Daily and regular intake of phenolic compounds present in natural foods is associated with reduced risk of serious health disorders because of their antioxidant activity (Solomon et al., 2006; Pan et al., 2019). Additionally, natural antioxidants are attracting more attention due to safety concerns of synthetic antioxidants (Shahidi and Ambigaipalan, 2015). Previously, few studies focused on phenols contained in rapeseed oil (Koski et al., 2002, 2003; Siger et al., 2008), compared to its meal (Vermorel et al., 1987; Amarowicz et al., 2000; Vuorela et al., 2004; Khattab et al., 2013; Szydłowska-Czerniak and Tułodziecka, 2014), since a large proportion of phenolic compounds is still in rapeseed meal after seed oil pressing (Naczk and Amarowicz, 1998).

Phenolic compounds are known for their antioxidative effects which are the most important characteristic of their free-radical scavenging capacity and metal ions chelation (Cotelle, 2001). To the best of our knowledge, only few methods were used for the determination of rapeseed oil antioxidant capacity, mainly, 2,2 -diphenyl-1-picrylhydrazyl (DPPH) and ferric-reducing antioxidant power (FRAP) (Siger et al., 2008, Szydłowska-Czerniak and Laszewska, 2015; Tundis et al., 2016). Neverthless, the ABTS method was only reported once by SzydłowskaCzerniak and Łaszewska (2015).

As far as we know, there is no study that emphasizes phenolics content and antioxidant activity of rapeseed oil in north-Africa. Hence, this work is a comparative study of oil samples extracted from nine promising advanced $\mathrm{M}_{2}$ rapeseed mutant lines and the wild-type variety 'INRACZH2' (check). This study was designed (i) to determine seed oil content and its fatty acid composition, (ii) to measure total phenolics content (TPC) and (iii) to evaluate the free-radical scavenging capacity. This work involves several data which include oil biochemical attributes of interest in order to emphasize and discriminate potential rapeseed mutant oils. Both correlation analysis and principal component analysis (PCA) were performed. This aims to develop rapeseed mutants with beneficially altered fatty acid composition and high level of TPC and antioxidant capacity. 


\section{Materials and methods}

\section{Plant material}

Plant material used in this study concerned nine promising advanced $\mathrm{M}_{2}$ mutants lines compared to the check variety 'INRA-CZH2' of rapeseed (Brassica napus L.). They were harvested on July 2016 from experimental station of Douyet of the National Institute for Agriculture Research (INRA) of Morocco. For each line, a representative sample of five plants was randomly chosen. Two years ago, physical (gamma rays) and chemical mutagen (Ethyl Methane Sulphonate, EMS) were applied to induce mutations in seed materials. In fact, 'INRACZH2' seeds were treated using gamma rays (1300 Gy) and four EMS concentrations (1, 1.2, 1.4 and $1.6 \%)$. They were also treated using both mutagenic agents in combination $(0.8 \%$ EMS + 1100 Gy) (Channaoui et al., 2019). The obtained $\mathrm{M}_{1}$ plants were evaluated in contrasted environments and the most interesting were selected and selfed to produce $\mathrm{M}_{2}$ lines. Code of each mutant line and the mutagenic treatments from which they were developed are described in Table 1.

\section{Seed oil extraction}

Rapeseed oil was extracted using the Soxhlet apparatus. Twenty grams of ground seeds were mixed with $150 \mathrm{~mL}$ of hexane for 2 hours at $130^{\circ} \mathrm{C}$. The solvent was evaporated at $40{ }^{\circ} \mathrm{C}$ using a rotavapor. The oil weight was determined as follows: Oil weight $(\%)=\left[\left(\mathrm{M}_{1}-\mathrm{M}_{0}\right) / \mathrm{M}_{2}\right] \times$ 100 , where $\mathrm{M}_{0}$ is the weight of the empty flask $(\mathrm{g}), \mathrm{M}_{1}$ the weight of the flask after evaporation (g) and $\mathrm{M}_{2}$ the weight of the ground seeds $(\mathrm{g})$. The resulting oil was kept away from light and stored at $4{ }^{\circ} \mathrm{C}$ until analysis.

\section{Fatty acid composition}

Fatty acid composition of the ten oil samples was determined by gas-liquid chromatography (GLC) of fatty acid methyl esters, prepared by simultaneous extraction and methylation following the procedure of Garcés and Mancha (1993). Fatty acid methyl esters were analyzed on a PerkinElmer Autosystem gas-liquid chromatograph (PerkinElmer Corporation, Norwalk, CT), equipped with a BPX70 capillary column of $30 \mathrm{~m}$ length, $0.25 \mathrm{~mm}$ of internal diameter, and $0.25 \mu \mathrm{M}$ film thickness (SGE Analytical Science Pty, Ltd., Ringwood, Australia). Hydrogen was used as carrier gas at a constant flow of $0.8 \mathrm{~mL} \mathrm{~min}{ }^{-1}$. The splitless injector and the flame ionization detector were maintained at $300{ }^{\circ} \mathrm{C}$. The initial oven temperature was 160 ${ }^{\circ} \mathrm{C}$ maintained for $2 \mathrm{~min}$, followed by a rate increase of $20^{\circ} \mathrm{C} \mathrm{min}^{-1}$ up to $250{ }^{\circ} \mathrm{C}$, maintained for 2 min. Fatty acids were identified by comparison of their retention times with standards. 


\section{Phenols extraction}

Extraction of phenolic compounds was carried out according to the method described by Tsimidou et al. (1992), with slight modifications. Two grams of oil sample were dissolved in $10 \mathrm{~mL}$ of hexane, and then added to $4 \mathrm{~mL}$ of methanol $60 \%(\mathrm{~V} / \mathrm{V})$. The mixture was subjected to an agitation during 2 hours at room temperature in darkness and then filtered through Whatman No.1 filter paper. All extractions were performed in triplicates. The three filtrates were combined, washed with $10 \mathrm{~mL}$ of hexane and stored at $4{ }^{\circ} \mathrm{C}$.

\section{Total phenolic content}

Total phenolic content (TPC) was determined using the Folin-Ciocalteu colourimetric method described by Favati et al. (1994). Briefly, $50 \mu \mathrm{L}$ of extract were mixed with $3 \mathrm{~mL}$ of distilled water, $250 \mu \mathrm{L}$ of Folin-Ciocalteu reagent and $750 \mu \mathrm{L}$ of sodium carbonate (7\%). The mixture was stirred for $8 \mathrm{~min}$ at room temperature and then $950 \mu \mathrm{L}$ of distilled water were added. After 2 hours of incubation in darkness, the absorbance was measured at $765 \mathrm{~nm}$ against a blank. Gallic acid was used as standard for the calibration curve. The results are expressed as mg equivalent of gallic acid (GAE) per $100 \mathrm{~g}$ of oil.

\section{Free radical scavenging activity (FRSA)}

FRSA of oil samples was determined following DPPH (2,2-diphenyl1-picrylhydrazyl) and cationic radical ABTS •+ (3-ethylbenzothiazoline-6-sulfonic acid) methods originally described by Brand-Williams et al. (1995) and Re et al. (1999), respectively, with slight modifications.

DPPH method: In brief, $50 \mu \mathrm{L}$ of oil extracts were mixed with $950 \mu \mathrm{L}$ of DPPH methanolic solution $\left(0.030 \mathrm{mg} \mathrm{mL}^{-1}\right)$. After $60 \mathrm{~min}$ of mixture incubation in darkness, the absorbance was measured at $515 \mathrm{~nm}$ against a reagent blank. The formula: [(Ac - Ae) / Ac] $\times 100$ was used to calculate the percentage of the free radical inhibition, where Ac is the absorbance of the control and Ae the absorbance of the sample. The half maximum inhibitory concentration, $\mathrm{IC}_{50}$ ( $\mu \mathrm{g}$ extract $\mathrm{mL}^{-1}$ ) was the inhibitory concentration at which DPPH radicals were scavenged by $50 \%$. It was calculated from the graph plotting inhibition percentage against oil extract dilutions (6$30 \mu \mathrm{g} / \mathrm{ml}$ ). For each sample, five concentrations were used and the average coefficient of determination of linear regression curves was about 0.978 . The $\mathrm{IC}_{50}$ value was inversely proportional to FRSA.

ABTS method: In our procedure, a solution of radical cation $\left(\mathrm{ABTS}^{\bullet+}\right)$ was produced by the reaction of $7 \mathrm{mM}$ of ABTS $\left(3.6 \mathrm{~g} \mathrm{~L}^{-1}\right)$ water solution with $2.45 \mathrm{mM}$ of potassium persulfate 
(0.662 $\left.\mathrm{g} \mathrm{L}^{-1}\right)$, followed by an incubation of the mixture in the dark for 18 hours at room temperature. Stock solution of $\mathrm{ABTS}^{\bullet+}$ was diluted with methanol until an absorbance of 0.700 \pm 0.05 at $734 \mathrm{~nm}$ was reached. Then, $10 \mu \mathrm{L}$ of extract or distilled water (control) were mixed with $990 \mu \mathrm{L}$ of diluted ABTS ${ }^{\bullet+}$ solution, and after 30 min of incubation in the dark, absorbance of this mixture was measured at $734 \mathrm{~nm}$. The percentage of the ABTS •+ inhibition was calculated using the following formula: $\left[\left(A_{c}-A_{e}\right) / A_{c}\right] \times 100$, where $A_{c}$ is the absorbance of the control and $\mathrm{A}_{\mathrm{e}}$ the absorbance of the extract.

\section{Statistical analysis}

All analyses were conducted on five oil samples per mutant line. One-way ANOVA, followed by Duncan's new multiple range test (DMRT), were performed to analyse significant differences between the studied lines. Mean differences were considered significant at $\mathrm{p}<0.05$ level. Pearson's correlation test was used to determine the associations between the investigated parameters. Also, principal component analysis (PCA) was performed using correlation matrix to determine whether various rapeseed lines could be grouped into different classes. Statistical analyses were conducted using SPSS software for Windows (Version 22).

\section{Results and discussion}

\section{Seed oil content}

Seed oil content (\%) of rapeseed $\mathrm{M}_{2}$ mutant lines and the control variety INRA-CZH2 is shown in Fig. 1. It can be noted that the rapeseed mutant lines contained significantly different amounts of oil ranging between 38.14 and 42.04\%. The mutant H2M-5 had the highest seed oil content (42.04\%), followed by the mutant H2M-7 which contained $40.9 \%$ of oil. The lowest value was found in the mutant H2M-9 (38.14\%), while the check variety averaged $39.37 \%$ (Fig. 1). These results were in agreement with those found in the literature (Rabiee et al., 2004; Iqbal et al., 2008; Sharafi et al., 2015).

\section{Fatty acids}

Fatty acid composition of rapeseed mutant lines exhibited significant variation, compared to the wild-type variety (Table 2). Oleic acid (18:1) was the pre-dominant fatty acid among all lines and ranged from 50.13 to $70.35 \%$. The mutant H2M-5 displayed $70.35 \%$ of $18: 1$, which is $6.58 \%$ higher than the check variety $(63.77 \%)$. However, the mutant H2M-4 showed $50.13 \%$ of 18:1 (13.64\% lower than the check). The variation of linoleic (18:2) and $\alpha$-linolenic acids (18:3) across lines was respectively in the range of $16.73-29.41 \%$ and $6.15-9.29 \%$. Palmitic 
acid (16:0) content (3.63-8.49\%) and stearic acid (18:0) content (1.63-2.5\%) also varied significantly among lines. The mutant H2M-4 exhibited the highest level of erucic acid 22: 1 $(0.26 \%)$, followed by the check variety then the mutant $\mathrm{H} 2 \mathrm{M}-8$, with average concentrations of 0.19 and $0.15 \%$, respectively. However, 22:1 was not detected in the other mutants (Table 2). Similarly, significant variation was observed in the amounts of saturated, poly and monounsaturated fatty acids among all lines (Table 2). Regarding total amount of saturated fatty acids (SAFA), the highest level was observed in the mutant H2M-4 (10.99\%), whereas the mutant H2M-5 had the lowest value (5.49\%) (Table 2). These two respective mutants also had the highest (38.68\%) and lowest $(22.89 \%)$ polyunsaturated fatty acid (PUFA) content. The H2M-4 mutant is also characterized by the highest ratio $\omega-6$ (18:3) / $\omega-3$ (18:2), which is 3.21 . The control variety had a SAFA content of $6.20 \%$, a PUFA content of $26.28 \%$ and a ratio of $\omega$ $6 / \omega-3$ of 2.71 .

Compared to the check variety (26.28\%), polyunsaturated fatty acids (PUFA) content was higher in H2M-4 (38.68\%). However, PUFA was lower in H2M-5 (22.89\%) (Table 2). Lee et al. (2018) reported three $\mathrm{M}_{2}$ mutants of Brassica napus L. (TR-130, TR-245 and TR-273) with PUFA averaging 41.9, 39.3 and $38.9 \%$, respectively. The same authors also reported the mutant (TR-932) with an average amount of SAFA about 19.3\%. The essential fatty acids, 18:2 and 18:3, raise a great interest because of the health potential of PUFA. Fatty acids were widely reported for their natural preventive function in cardiovascular diseases and effective plasma cholesterol-lowering activity (Faremi and Ekanem, 2011; Hooper et al., 2011). Moreover, PUFA are well-known for their ability to reduce total and LDL cholesterol, with a minor reduction in HDL cholesterol (Ajayi and Ajayi, 2009). Being superior in PUFA, the Mutant H2M-4 may present an interesting source of edible oil with possibly high standard rapeseed oil quality that may contribute to health-promoting human diet.

Amongst studied lines, the main fraction of fatty acids was monounsaturated fatty acids (MUFA), which varied from 50.33\% (H2M-4) to 71.62\% (H2M-5) (Table 2). Bouchereau et al. (1996) and Wittkop et al. (2009) reported that an increase in MUFA is accompanied with a decrease in erucic acid and vice-versa. In this study, all rapeseed lines exhibited minor amounts of erucic acid (0-0.26\%), which explains the high recorded levels of MUFA. Auld et al. (1992) stated that a reduced level of PUFA and an increased content of MUFA, particularly 18:3 and 18:1, respectively, provided higher oil stability and the resulting product can be used for food applications requiring high cooking and frying temperatures. Therefore, breeding rapeseed combining high 18:1 and low 18:3 contents is a major goal. Fatty acids profile analysis showed that the mutant H2M-5 had a higher level of 18:1 and lower content of 18:3. These results 
revealed some promising mutants with interesting genetic potential that can be used directly for oil production or as a source of desirable genes in rapeseed breeding programs.

Linoleic $(\omega-6)$ and linolenic $(\omega-3)$ acids ratio in all studied rapeseed lines ranged from 2.1 (H2M-6) to 3.21 (H2M-4) (Table 2). Being a critical parameter in human diet, the $\omega-6 / \omega-3$ is usually recommended to approach 4:1 (Yehuda and Carasso, 1993; Zhang et al., 2004). In our case, H2M-4 was found to meet the recommended specification with regard to $\omega-6 / \omega-3$, whereas, the others lines exhibited $\omega-6 / \omega-3$ less than the recommended value. Generally, since the majority of the vegetable seed oils presently in use fall short of these recommendations, they are usually marketed in blended forms (Singh et al., 2014).

\section{Total phenolic content}

The total phenolic contents (TPC) were expressed as gallic acid equivalent (GAE) and showed significant variability (Fig. 2). The highest TPC was obtained in the mutant H2M-1 (4.35 mg GAE $\left.100 \mathrm{~g}^{-1}\right)$, which is about twice, compared to the check (2.35 mg GAE $\left.100 \mathrm{~g}^{-1}\right)$, followed by the mutants H2M-5 and H2M-6 that averaged 3.57 and $3.34 \mathrm{mg}$ GAE $100 \mathrm{~g}^{-1}$, respectively. However, TPC was generally low in the other mutants whose values were in a narrow range of variation (Fig. 2).

The wide variability of TPC recorded in rapeseed varieties has been widely reported to be dependent mainly to the genotype, while small variation was attributed to agronomic and environmental factors (Shahidi and Naczk, 1992; Cai and Arntfield, 2001; Matthäus, 2002; Siger et al., 2004). Compared to rapeseed meal, only few studies reported TPC in the lipid fraction, using different individual phenols (acids) as standards. In their study on rapeseed, Szydłowska-Czerniak and Łaszewska (2015) reported that TPC varied from 5.4 to $21.8 \mathrm{mg}$ sinapic acid equivalent per $100 \mathrm{~g}$ of oil, while Chen et al. (2014) found that average TPC value was $10.7 \mathrm{mg}$ sinapic acid equivalent per $100 \mathrm{~g}$ of oil. In other older work, Siger et al. (2008) reported that TPC was $1.31 \mathrm{mg}$ caffeic acid equivalent per $100 \mathrm{~g}$ of rapeseed oil. One could observe higher values for sinapic acid equivalent as this individual phenol has a higher contribution to the total phenolic content. On the other hand, Bopitiya and Madhujith (2013) reported that TPC in sesame oil was about $0.26 \mathrm{mg}$ gallic acid equivalent per $100 \mathrm{~g}$, indicating that rapeseed is richer in total phenols than sesame.

\section{Free radical scavenging activity (FRSA)}

Results of FRSA were expressed as \% of inhibition and are summarized in Fig. 3. Significant variability was revealed among lines regarding the two methods. In the DPPH essay, the highest 
FRSA was recorded by H2M-1 and H2M-5, having respective values of 59.28 and $53.29 \%$, whereas, the lowest FRSA average value was observed in H2M-10 (40.5\%) (Fig. 3). For ABTS essay, the mutant H2M-1 had the highest FRSA which averaged 59.86\%, followed by H2M-5, with a mean value of $49.69 \%$. However, the lowest values did not exceed $40.5 \%$ and were recorded in H2M-9 and H2M-7, with respective average values of 40.31 and $40.43 \%$ (Fig. 3). It is noteworthy that DPPH values were almost similar in comparison to ABTS results for most of rapeseed lines. Furthermore, the lines that showed the highest FRSA (DPPH and ABTS) values also recorded the highest amounts of TPC.

Fig. 4 shows the half-maximal inhibition concentration (IC50) concerning DPPH essay. The extract from mutant H2M-1 exhibited the lowest $\mathrm{IC}_{50}$ value $\left(24.31 \mu \mathrm{g} \mathrm{mL} \mathrm{m}^{-1}\right)$, thereby demonstrating the best ability to stabilize reactive DPPH radicals via the electron donor mechanism (Hassas-Roudsri, 2009). Similarly, H2M-5 averaged $26.96 \mu \mathrm{g} \mathrm{mL}{ }^{-1}$, which indicates a promising $\mathrm{IC}_{50}$. This means that the extracts from the both mutants had the highest free radical scavenging capacity. Knowing that phenols are the major contributors in FRSA, H2M-1 and H2M-5 recorded the highest amounts of TPC (4.35 and $3.57 \mathrm{mg}$ GAE $100 \mathrm{~g}^{-1}$, respectively) which explains their capacity to neutralize DPPH radicals (Figs. 2, 3). Siger et al. (2008) confirmed the antioxidant activity of rapeseed oil extracts which scavenged $51.2 \%$ of DPPH radicals. Vuorela et al. (2004) also reported strong antioxidant properties of phenolic compounds which scavenged over $60 \%$ of DPPH radicals. These results might not only be influenced by the amount of total phenolic content, but also by the presence of some specific phenolic compounds in the methanolic extracts of rapeseed oil that were not studied in our work, e.g., vinylsyringol (canolol). This compound is probably the product of sinapic acid decarboxylation, which has strong antioxidant potential (Koski et al., 2003). It was mentioned that scavenging DPPH by phenolic compounds depended on the number of hydroxyl groups in the aromatic ring of the studied compounds (Siger et al., 2008).

\section{Correlation among biochemical attributes}

Pearson's correlation coefficients among the biochemical traits evaluated in this study were computed (Table 3). SAFA had highly significant and negative correlation with MUFA ( $\mathrm{r}=-$ 0.939, $\mathrm{p}<0.01)$ and highly significant and positive correlation with PUFA $(\mathrm{r}=0.871, \mathrm{p}<0.01)$. A negative and highly significant association was observed between MUFA and PUFA ( $\mathrm{r}=-$ 0.975, $\mathrm{p}<0.01)$. The relationship of $\omega-6 / \omega-3$ was significantly positive with PUFA $(r=0.648$, $\mathrm{p}<0.05)$, and significantly negative with MUFA $(\mathrm{r}=-0.642, \mathrm{p}<0.05)$. These correlations seem 
evident since the increase in MUFA is usually associated with the decrease in SAFA and PUFA levels.

On the other hand, TPC was positively and significantly correlated to the antioxidant capacity determined by DPPH and ABTS essays $(r=0.801$ and $0.802, \mathrm{p}<0.01)$. In this case, high phenolic content is an important factor in determining the antioxidant capacity of rapeseed oil. Concordantly, significant correlation between antioxidant capacity and TPC was reported by Szydłowska-Czerniak et al. (2010) in seven winter rapeseed varieties using DPPH $(r=0.9516)$ and FRAP ( $\mathrm{r}=0.9468)$ methods. However, in a previous study, a strong and significant correlation $(r=0.966)$ between the reducing power of 'Cyclone' canola hull extract and TPC was recorded (Amarowicz et al., 2000). Besides, significant correlation $(r=0.694, p<0.05)$ was found between the two analytical methods: DPPH and ABTS used to determine the antioxidant potential of rapeseed lines. In addition, a negative and highly significant correlation was observed between the DPPH method and the $\operatorname{IC}_{50}(-0.938, \mathrm{p}<0.01)$.

In contrast with most previous reports, Tacoltt et al. (2005) and Vermaak et al. (2011) have found that DPPH radical scavenging activity was positively correlated to the oleic acid rates in some vegetable oils. They speculated that the high amounts of monounsaturated oleic acid may be a key to the radical scavenging capacity of the lipids. Moreover, since biochemical data on rapeseed oil are scare, the findings could be an effective introduction to the antioxidant activities of this species, which can make it a potential natural source of antioxidants for the food industry and other fields. In fact, M2 rapeseed mutant lines exhibited interesting levels of antioxidant potency. However, further investigation on chemical compositions and other properties is required to evaluate for more in-depth discrimination of those mutants.

\section{Principal Component Analysis}

Principal component analysis (PCA) based on correlation coefficient was applied to the variables studied in order to determine discriminant variables in the data set. This method aims to define the principal components for reducing the number of variables to observe any possible clusters within analysed rapeseed oil samples. The first two principal components accounted for $76.56 \%$ ( $\mathrm{PC} 1=39.88 \%$ and $\mathrm{PC} 2=36.68 \%$, respectively $)$ of total variance. Actually, $\mathrm{PC} 1$ was defined by DPPH (0.810), TPC (0.757), IC50 (-0.730) and ABTS (0.673), which means that the first component discriminates lines based on their antioxidants amount. PC2 was correlated to SAFA (0.847), MUFA (-0.829), PUFA (0.802) and $\omega-6 / \omega-3$ (0.561) (Table 4). This indicates 
that the second component separates lines for their fatty acids composition, first, and then for the ratio $\omega-6 / \omega-3$.

Scatter plot was prepared according to the PC1 and PC2 in order to assess rapeseed lines distribution (Fig. 5). The studied rapeseed $\mathrm{M}_{2}$ mutants fell into four distinct groups. The mutant H2M-4 was largely distinguished from other lines, based on its low levels of TPC, DPPH, ABTS and MUFA, and its high amounts of SAFA and PUFA. Similarly, the mutant H2M-1 was classified distinctively from all lines. It recorded high levels of TPC, DPPH, ABTS, SAFA, PUFA and $\omega-6 / \omega-3$. However, it exhibited a low amount of MUFA. This classification can be explained by the fact that this mutant contained about two times higher amount of TPC (4.35 mg GAE/100 g) than other rapeseed lines. The mutants H2M-5, H2M-6 and H2M-11, were clustered in a distinct subset. This similarity is explained by their high concentration of MUFA and low levels of SAFA and PUFA. They also exhibited very close amounts of TPC and FRSA based on the two methods. Being located in the same quarter of the PCA plot, the mutants H2M7, H2M-8, H2M-9 and H2M-10 seemed to be no different from the check variety. They were characterized by low TPC, DPPH and ABTS levels (Fig. 5).

\section{Conclusion}

There is no study emphasizing Moroccan rapeseed oil quality within a novel germplasm generated by mutagenesis. The present work targeted fatty acids composition and antioxidant capacity of phenolic compounds in oil of nine rapeseed selected $\mathrm{M}_{2}$ mutants. The results indicated that oil content and composition varied significantly among all mutants. Compared to the check variety and the other mutants, H2M-5 revealed the highest seed oil content and the highest MUFA fraction, where oleic acid was about 70\%, which concomitantly implies a decrease in linoleic and linolenic acids amounts. On the other hand, the mutant H2M-4 presented the highest proportion of SAFA and PUFA. Consequently, H2M-4 may be proposed as an interesting natural source of edible oil containing high amounts of healthy polyunsaturated fatty acids. As they showed altered fatty acids composition, H2M-4 and H2M-5 may be integrated in a rapeseed breeding program. Furthermore, total phenolics amount showed significant variation across mutants. In fact, the mutant H2M-1 exhibited the highest level (4.35 mg GAE/100 g), which is about twice that of other mutants. This trend was also confirmed by the FRSA, using DPPH and ABTS methods, as the highest FRSA was recorded by H2M-1. It is noteworthy that SAFA were correlated significantly and positively to PUFA, but negatively to MUFA in all oil samples. Being the most important contributors in radical scavenging process, TPC were highly correlated to FRSA regarding the two methods. Finally, H2M-1, 
H2M-4 and H2M-5 were selected as superior mutants that need to be evaluated for their stability and used as genitors in order to combine the traits of interest. This is the first report about selection of rapeseed mutants using fatty acids and biochemical markers in North-Africa.

\section{References}

Ajayi, O. B., \& Ajayi, D. D. (2009) Effect of oilseed diets on plasma lipid profile in albino rats. Pakistan Journal of Nutrition, 8:116-118.

Amarowicz, R., Naczk, M., \& Shahidi, F. (2000) Antioxidant activity of various fractions of non-tannin phenolics of canola hulls. Journal of Agricultural and Food Chemistry, 48, 2755-2759. https://doi.org/10.1021/jf9911601

Auld, D. L., Heikkinen, M. K., Erickson, D. A., Sernyk, J. L., \& Romero, J. E. (1992) Rapeseed mutants with reduced levels of polyunsaturated fatty acids and increased levels of oleic acid. Crop Science, 32:657-662.

Brand-Williams, W., Cuvelier, M. E., \& Berset, C. L. W. T. (1995) Use of a free radical method to evaluate antioxidant activity. LWT-Food science and Technology, 28:25-30. https://doi.org/10.1016/S0023-6438(95)80008-5

Bopitiya, D., \& Madhujith, T. (2013) Antioxidant activity and total phenolic content of sesame (Sesamum indicum L.) seed oil. Tropical Agricultural Research, 24:296-302.

Bouchereau, A., Clossais-Besnard, N., Bensaoud, A., Leport, L., \& Renard, A. M. (1996) Water stress effects on rapeseed quality. European Journal of Agronomy, 5:19-30. https://doi.org/10.1016/S1161-0301(96)02005-9

Cai, R., \& Arntfield, S. D. (2001) A rapid high-performance liquid chromatographic method for the determination of sinapine and sinapic acid in canola seed and meal. Journal of the American Oil Chemists' Society, 78:903-910.

Channaoui, S., Labhilili, M., Mouhib, M., Mazouz, H., El Fechtali, M., \& Nabloussi, A. (2019) Development and evaluation of diverse promising rapeseed (Brassica napus L.) mutants using physical and chemical mutagens. Oilseeds and fats, Crops and Lipids, 26:35. https://doi.org/10.1051/oc1/2019031

Chen, Y., Thiyam-Hollander, U., Barthet, V. J., \& Aachary, A. A. (2014) Value-added potential of expeller-pressed canola oil refining: Characterization of sinapic acid derivatives and tocopherols from byproducts. Journal of Agricultural and Food Chemistry, 62:98009807. https://doi.org/10.1021/jf502428z

Cotelle, N. (2001) Role of flavonoids in oxidative stress. Current Topics in Medicinal Chemistry, 1:569-590. https://doi.org/10.2174/1568026013394750

Deng, X., \& Scarth, R. (1998) Temperature effects on fatty acid composition during Sdevelopment of low- linolenic oilseed rape (Brassica napus L.). Journal of the American Oil Chemists' Society, 75:759-766. https://doi.org/10.1007/s11746-998$\underline{0223-4}$

Garcés, R., \& Mancha, M. 1993. One step lipid extraction and fatty acid methyl esters preparation from fresh plants tissues. Analytical Biochemistry, 211: 139-143. https://doi.org/10.1006/abio.1993.1244 
Graef, G., LaVallee, B. J., Tenopir, P., Tat, M., Schweiger, B., Kinney, A. J., Van Gerpen, J. H., \& Clemente, T. E. (2009) A high- oleic- acid and low- palmitic- acid soybean: agronomic performance and evaluation as a feedstock for biodiesel. Plant Biotechnology Journal, 7:411-421. https://doi.org/10.1111/j.1467-7652.2009.00408.x

Hassas-Roudsri, M., Chang, P. R., Pegg, R. B., \& Tyler, R. T. (2009) Antioxidant capacity of bioactives extracted from canola meal by subcritical water, ethanolic and hot water extraction. Food Chemistry, 114:717-726.

https://doi.org/10.1016/j.foodchem.2008.09.097

Hooper, L., Summerbell, C. D., Thompson, R., Sills, D., Roberts, F. G., Moore, H., \& Smith, G. D. (2011). Reduced or modified dietary fat for preventing cardiovascular disease. Cochrane database of systematic reviews, 7.

https://doi.org/10.1002/14651858.CD002137.pub2

FAOSTAT. (2018) Available at: http://www.fao.org/faostat/en/\#data/. (Accessed on 12 April 2018).

Faremi, A. Y., \& Ekanem, J. T. (2011) Haematological parameters and enzyme studies in Trypanosome brucei-infected rats reared on Nigella sativa oil-based diet. Asian Journal of Biochemistry, 6:90-97.

Favati, F., Caporale, G., \& Bertuccioli, M. (1994) Rapid determination of phenol content in extra virgin olive oil. Grasas y Aceites, 45:68-70.

https://doi.org/10.3989/gya.1994.v45.i1-2.974

Huang, X. Q., Huang, T., Hou, G. Z., Li, L., Hou Y., \& Lu Y. H. (2016) Identification of QTLs for seed quality traits in rapeseed (Brassica napus L.) using recombinant inbred lines (RILs). Euphytica, 210:1-16. doi: 10.1007/s10681-016-1675-5

Iqbal, M., Akhtar, N., Zafar, S. \& Ali, I. (2008) Genotypic responses for yield and seed oil quality of two Brassica species under semi-arid environmental conditions. South African Journal of Botany, 74:567-571. https://doi.org/10.1016/j.sajb.2008.02.003

Jang, Y. S., Kim, K. S., Lee, Y. H., Cho, H. J., \& Suh, S. J. (2010) Review of property and utilization of oil crop for biodiesel. Journal of Plant Biotechnology, 37:25-46. https://doi.org/10.5010/JPB.2010.37.1.025

Khattab, R., Eskin, M., Aliani, M., \& Thiyam, U. (2010) Determination of sinapic acid derivatives in canola extracts using high-performance liquid chromatography. Journal of the American Oil Chemists' Society, 87:147-155. https://doi.org/10.1007/s11746$\underline{009-1486-0}$

Koski, A., Psomiadou, E., Tsimidou, M., Hopia, A., Kefalas, P., Wähälä, K., \& Heinonen, M. (2002) Oxidative stability and minor constituents of virgin olive oil and cold-pressed rapeseed oil. European Food Research and Technology, 214:294-298. https://doi.org/10.1007/s00217-001-0479-5

Koski, A., Pekkarinen, S., Hopia, A., Wähälä, K., \& Heinonen, M. (2003) Processing of rapeseed oil: effects on sinapic acid derivative content and oxidative stability. European Food Research and Technology, 217:110-114. https://doi.org/10.1007/s00217-003$\underline{0721-4}$ 
Lee, Y. H., Kim, K. S., Jang, Y. S., Cho, H. J., Nam, S. S., \& Suh, S. J. (2010) Breeding of F1 hybrid rapeseed and the cultivation for biodiesel production in Korea. The Journal of the Korean Society of International Agriculture, 22:341-345.

Lee, Y. H., Park, W., Kim, K. S., Jang, Y. S., Lee, J. E., Cha, Y. L., Moon, Y. H., Song, Y. S., \& Lee, K. (2018) EMS-induced mutation of an endoplasmic reticulum oleate desaturase gene (FAD2-2) results in elevated oleic acid content in rapeseed (Brassica napus L.). Euphytica, 214:28. https://doi.org/10.1007/s10681-017-2106-y

Liu, J. W., DeMichele, S., Bergana, M., Bobik, E., Hastilow, C., Chuang, L. T., Mukerji, P., \& Huang, Y. S. (2001) Characterization of oil exhibiting high $\gamma$-linolenic acid from a genetically transformed canola strain. Journal of the American Oil Chemists' Society, 78:489-493. https://doi.org/10.1007/s11746-001-0291-2

Matthäus, B. (2002). Antioxidant activity of extracts isolated from residues of oilseeds, such as rapeseed or sunflower. Agro Food Industry Hi-Tech, 13: 22-25.

Naczk, M., Amarowicz, R., Sullivan, A., \& Shahidi, F. (1998) Current research developments on polyphenolics of rapeseed/canola: A review. Food Chemistry, 62:489-502. https://doi.org/10.1016/S0308-8146(97)00198-2

Nesi, N., Delourme, R., Brégeon, M., Falentin, C., \& Renard, M. (2008) Genetic and molecular approaches to improve nutritional value of Brassica napus L. seed. Comptes rendus biologies, 331:763-771. https://doi.org/10.1016/j.crvi.2008.07.018

Pan, Y., Wang, Y., Fan, X., Wang, W., Yang, X., Cui, D., \& Zhao, M. (2019) Bacterial intracellular nanoparticles exhibiting antioxidant properties and the significance of their formation in ROS detoxification. Environmental microbiology reports, 11:140-146. https://doi.org/10.1111/1758-2229.12733

Rabiee, M., Karimi, M. M., \& Safa, F. (2004) Effect of planting dates on grain yield and agronomical characters of rapeseed cultivars as a second crop after rice at Kouchesfahan. Iranian Journal of Agricultural Science, 35:177-187.

Re, R., Pellegrini, N., Proteggente, A., Pannala, A., Yang, M., \& Rice-Evans, C. (1999) Antioxidant activity applying an improved ABTS radical cation decolorization assay. Free radical biology and medicine, 26:1231-1237. https://doi.org/10.1016/S0891-5849(98)00315-3

Röbbelen, G., \& Kräling, K. (1993) Rapeseed oils high in single fatty acid contents for oleochemical uses. Industrial Crops and Products, 1:303-309. https://doi.org/10.1016/0926-6690(92)90032-Q

Shahidi, F., \& Naczk, M. (1992) An overview of the phenolics of canola and rapeseed: chemical, sensory and nutritional significance. Journal of the American Oil Chemists' Society, 69:917-924. https://doi.org/10.1007/BF02636344

Shahidi, F., \& Ambigaipalan, P. (2015) Phenolics and polyphenolics in foods, beverages and spices: Antioxidant activity and health effects-A review. Journal of Functional Foods, 18:820-897. https://doi.org/10.1016/j.jff.2015.06.018

Sharafi Y, Majidi M. M., Goli S. A. H., \& Rashidi, F. (2015) Oil content and fatty acids composition in Brassica species. International Journal of Food Properties, 18:21452154. https://doi.org/10.1080/10942912.2014.968284 
Siger, A., Nogala-Kałucka, M., Lampart-Szczapa, E., \& Hoffmann, A. (2004) Phenolic compound contents in new rape varieties. Oilseed crops, 1:263-274.

Siger A, Nogala-Kalucka, M., \& Lampart-Szczapa, E. (2008). The content and antioxidant activity if phenolic compounds in cold-pressed plant oils. Journal offood lipids, 15:137149. https://doi.org/10.1111/j.1745-4522.2007.00107.x

Singh, B., Bala, M., \& Rai, P. (2014) Fatty Acid Composition and Seed Meal Characteristics of Brassica and Allied Genera. National Academy Science Letters, 37:219-226. https://doi.org/10.1007/s40009-014-0231-X

Solomon, A., Golubowicz, S., Yablowicz, Z., Grossman, S., Bergman, M., Gottlieb, H.E., Altman, A., Kerem, Z., \& Flaishman, M.A. (2006) Antioxidant activities and anthocyanin content of fresh fruits of common fig (Ficus carica L.). Journal of Agricultural and Food Chemistry, 54:7717-7723. https://doi.org/10.1021/jf060497h

Szydłowska-Czerniak, A., Trokowski, K., Karlovits, G., \& Szłyk, E. (2010) Determination of antioxidant capacity, phenolic acids, and fatty acid composition of rapeseed varieties. Journal of agricultural and food chemistry, 58:7502-7509. https://doi.org/10.1021/jf100852x

Szydłowska-Czerniak, A., \& Tułodziecka, A. (2014) Antioxidant capacity of rapeseed extracts obtained by conventional and ultrasound-assisted extraction. Journal of the American Oil Chemists' Society, 91:2011-2019. https://doi.org/10.1007/s11746-014-2557-4

Szydłowska-Czerniak, A., \& Łaszewska, A. (2015) Effect of refining process on antioxidant capacity, total phenolics and prooxidants contents in rapeseed oils. LWT-Food Science and Technology, 64:853-859. https://doi.org/10.1016/j.lwt.2015.06.069

Talcott, S. T., Duncan, C. E., Del Pozo-Insfran, D., \& Gorbet, D. W. (2005) Polyphenolic and antioxidant changes during storage of normal, mid, and high oleic acid peanuts. Food Chemistry, 89:77-84. https://doi.org/10.1016/j.foodchem.2004.02.020

Tsimidou, M., Papadopoulos, G., \& Boskou, D. (1992). Phenolic compounds and stability of virgin olive oil-Part I. Food Chemistry, 45:141-144. https://doi.org/10.1016/0308$\underline{8146(92) 90025-\mathrm{W}}$

Tundis, R., Tenuta, M. C., Loizzo, M. R., Bonesi, M., Menichini, F., \& Duthie, G. (2016) Natural compounds and vegetable powders improve the stability and antioxidant properties of Brassica napus L. var.oleifera (rapeseed) oil. European Journal of Lipid Science and Technology, 118:0000-0000. https://doi.org/10.1002/ejlt.201600228

Vermaak, I., Kamatou, G. P. P., Komane-Mofokeng, B., Viljoen, A. M., \& Beckett, K. (2011) African seed oils of commercial importance-Cosmetic applications. South African Journal of Botany, 77:920-933. https://doi.org/10.1016/j.sajb.2011.07.003

Vermorel, M., Hocouemiller, R., \& Evrard, J. (1987) Valorization of rapeseed meal. 5. Effects of sinapine and other phenolic compounds on food intake and nutrient utilization in growing rats. Reproduction Nutrition Development, 27:781-790.

Vuorela, S., Meyer, A. S., \& Heinonen, M. (2004) Impact of isolation method on the antioxidant activity of rapeseed meal phenolics. Journal of agricultural and food chemistry, 52:8202-8207. https://doi.org/10.1021/jf0487046 
Wanasundara, J. P. D., Mcintosh, T. C., Perera, S. P., Withana-Gamage, T. S., \& Mitra, P. (2016) Canola/rapeseed protein-functionality and nutrition. OCL, 23:D407. https://doi.org/10.1051/ocl/2016028

Warner, K., \& Knowlton, S. (1997) Frying quality and oxidative stability of high- oleic corn oils. Journal of the American Oil Chemists' Society, 74:1317-1322. https://doi.org/10.1007/s11746-997-0063-7

Wittkop, B., Snowdon, J., \& Friedt, W. (2009) Status and perspectives of breeding for enhanced yield and quality of oilseed crops for Europe. Euphytica, 170:131-140. https://doi.org/10.1007/s10681-009-9940-5

Yang, Q., Fan, C., Guo, Z., Qin, J., Wu, J., Li, Q., Fu, T., \& Zhou, Y. (2012) Identification of FAD2 and FAD3 genes in Brassica napus genome and development of allele-specific markers for high oleic acid and low linolenic acid contents. Theoretical and applied genetics, 125:715-729. https://doi.org/10.1007/s00122-012-1863-1

Yang, M., Zheng, C., Zhou, Q., Liu, C., Li, W., \& Huang, F. (2014) Influence of microwaves treatment of rapeseed on phenolic compounds and canolol content. Journal of Agricultural and Food Chemistry, 62:1956-1963. https://doi.org/10.1021/jf4054287

Yehuda, S., \& Carasso, R. L. (1993) Modulation of learning, pain thresholds, and thermoregulation in the rat by preparations of free purified alpha-linolenic and linoleic acids: determination of the optimal omega 3-to-omega 6 ratio. Proceedings of the National Academy of Sciences, 90:10345-10349. https://doi.org/10.1073/pnas.90.21.10345

Zanetti, F., Vamerali, T., \& Mosca, G. (2009) Yield and oil variability in modern varieties of high-erucic winter oilseed rape (Brassica napus L. var. oleifera) and Ethiopian mustard (Brassica carinata A. Braun) under reduced agricultural inputs. Industrial crops and products, 30:265-270.https://doi.org/10.1016/j.indcrop.2009.05.002

Zhang, H., Shi, C., Wu, J., Ren, Y., Li, C., Zhang, D., \& Zhang, Y. (2004) Analysis of genetic effects and heritabilities for linoleic and $\alpha$ - linolenic acid content of Brassica napus L. across Chinese environments. European journal of lipid science and technology, 106:518-523. https://doi.org/10.1002/ejlt.200400963 